\title{
Estimate Electrical Resistivity of Epoxy Insulators Using Artificial Neural Network
}

\author{
L. S. Nasrat ${ }^{1}$, A. A. Ibrahim ${ }^{1}$, W. A. Abdelamgied ${ }^{2 *}$ and S. A. Qenawy ${ }^{3}$ \\ ${ }^{\mathrm{T}}$ Electrical Engineering Department, Aswan University, Aswan, Egypt \\ ${ }^{2}$ Maintenance Department, El Marwa Company, Luxor, Egypt \\ ${ }^{3}$ Electrical Engineering Department, the High Institute of Engineering and Technology at Eltod, Luxor, Egypt
}

\section{*Corresponding Author}

Walaa A. Abdelamgied

\author{
Article History \\ Received: 25.06 .2020 \\ Accepted: 02.07.2020 \\ Published: 09.07.2020
}

\begin{abstract}
Epoxy resin represents a commonly used basis for insulation materials and has been used in many different electrical applications. In this paper, different micro fillers such as Silicone dioxide $\left(\mathrm{SiO}_{2}\right)$ and $\mathrm{Barium}$ iodate $\left(\mathrm{Ba}\left(\mathrm{IO}_{3}\right)_{2}\right)$ were added to epoxy resin to improve electrical characteristics in different contaminated conditions. The electrical resistivity (ohm.cm) was carried out. The samples were prepared by mixing micro filler into epoxy with the content of $0,5,10,15,20$ and $25 \mathrm{wt} \%$. The artificial neural network (ANN) technique was used to evaluate electrical resistivity in different contaminated conditions and different fillers concentrations. The results show that the electrical resistivity of epoxy composites is increased with the increase of filler concentration. Maximum electrical resistivity (ohm.cm) value was obtained from micro Barium iodate composite with $25 \mathrm{wt} \%$ filler concentration.
\end{abstract}

Keywords: Epoxy resin, Silicone dioxide filler, Barium iodate filler, Electrical resistivity, Artificial neural network.

\section{INTRODUCTION}

Epoxy resin insulators have been successfully used in high voltage equipment for AC systems for more than 60 years. Epoxy resins are ideal for these applications because of their high specific stiffness, high specific strength, electrical insulating properties, corrosion resistance, chemical compatibility with reinforcing fibers, and relative ease of manufacture [1].

Fillers are often added to epoxy resin to enhance its mechanical, thermal and chemical properties. The addition of fillers can deteriorate electrical performance. With the new development in nanotechnology, it has been widely anticipated that the combination of nanoparticles with traditional resin systems may create nanocomposite materials with enhanced electrical, thermal and mechanical properties [2-6].

Epoxy resins were first commercialized from seventy years and are widely used in industry as protective coatings and for structural applications, such as laminates and composites, tooling, molding, casting, bonding and adhesives, and others. The ability of the epoxy ring to react with a variety of substrates gives the epoxy resins versatility [7].

\section{EXPERIMENTAL Samples Preparation}

The filler is loaded to the resin/hardener mixture which is again stirred slowly till the particles have been uniformly mixed with the resin under the magnetic field and the air bubbles have escaped. The mixture is then poured carefully into a mold and left at room temperature $\left(25^{\circ} \mathrm{C} \pm 1\right)$ until curing after 24 hours and 7 days for material stability. The mixture of epoxy composite takes the mold shape. There are different ratios of each filler $\mathrm{SiO} 2$ and $\mathrm{Ba}$ (IO3)2 (5 up

Copyright @ 2020: This is an open-access article distributed under the terms of the Creative Commons Attribution license which permits unrestricted use, distribution, and reproduction in any medium for non commercial use (NonCommercial, or CC-BY-NC) provided the original author and source are credited. 
to $25 \%$ by weight). The mixing formulation of epoxy composite samples at different types and concentrations of fillers is given in Table 1.

Table-1: The Mixing formulation of epoxy with different type and concentration of fillers

\begin{tabular}{|c|c|c|}
\hline \multirow{2}{*}{ Filler concentration } & \multicolumn{2}{|c|}{ Filler type } \\
\cline { 2 - 3 } & $\mathbf{S i O}_{\mathbf{2}}$ & $\mathbf{B a}\left(\mathbf{I O}_{\mathbf{3}}\right)_{\mathbf{2}}$ \\
\hline 0 & $\mathrm{P}$ & $\mathrm{P}$ \\
\hline 5 & $\mathrm{Si}_{5}$ & $\mathrm{Ba}_{5}$ \\
\hline 10 & $\mathrm{Si}_{10}$ & $\mathrm{Ba}_{10}$ \\
\hline 15 & $\mathrm{Si}_{15}$ & $\mathrm{Ba}_{15}$ \\
\hline 20 & $\mathrm{Si}_{20}$ & $\mathrm{Ba}_{20}$ \\
\hline 25 & $\mathrm{Si}_{25}$ & $\mathrm{Ba}_{25}$ \\
\hline
\end{tabular}

\section{Electrical Resistivity Test}

Reading of resistance is recorded by meter as shown in Fig-1 and Fig-2 [8-9]. Resistivity depends on the value of resistance and the sample dimensions. The electrical resistivity $(\rho)$ of a solid material is determined by passing an electric current through a specimen and then measuring the resultant voltage drop over a certain length. the electrical resistivity formula can be written as (1):

Where,

$$
\rho=\frac{R \cdot A}{L}
$$

$\mathrm{R}$ : is the electrical resistance of a uniform specimen (ohms: $\Omega$ )

$\mathrm{A}$ is the cross-sectional area of the specimen $\left(\mathrm{cm}^{2}\right)$

$\mathrm{L}$ is the length of the specimen $(\mathrm{cm})$

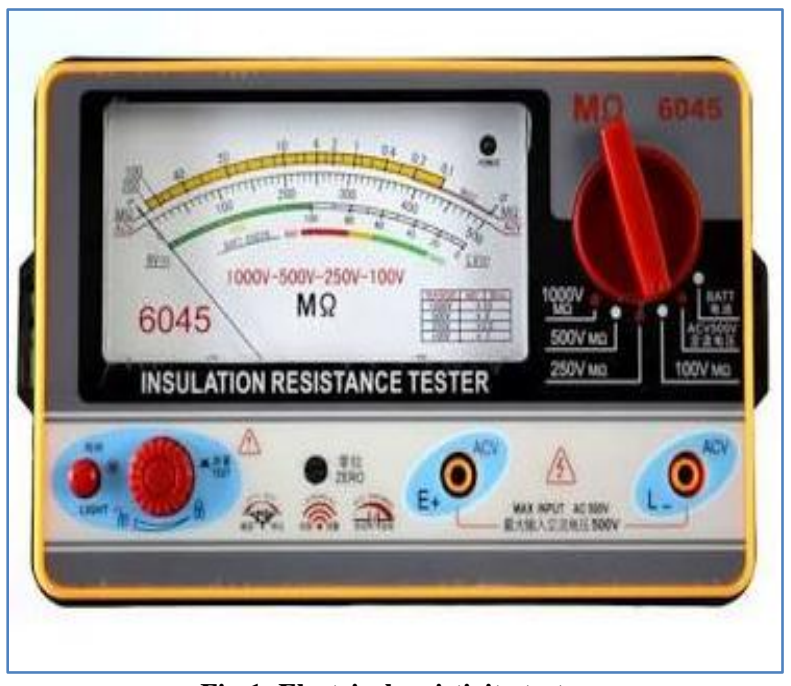

Fig-1: Electrical resistivity tester

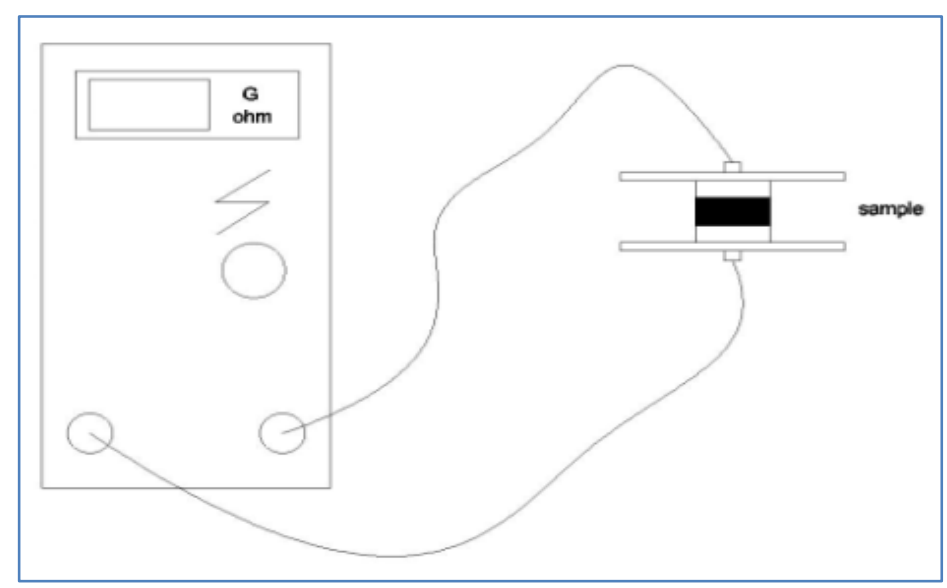

Fig-2: Schematic diagram of resistivity test arrangement for insulator 


\section{Artificial Neural Network Simulation}

In several fields artificial intelligence (AI) is used more and more frequently: for control, fail detection, or to predict variables. One of the most widely used AI tools is the neural network, and the most widely used neural network architecture is the multilayer feed forward Fig-3. As proved in the universal approximation theorem [10] a feed-forward network with a single hidden layer, is capable of approximating any continuous functions defined on compact training data sets. It is common to apply the classical training algorithm, based on the minimization of the mean squared error (MSE) cost function, with the process (training) data. A comprehensive fundamentals of ANN can be found in [11].

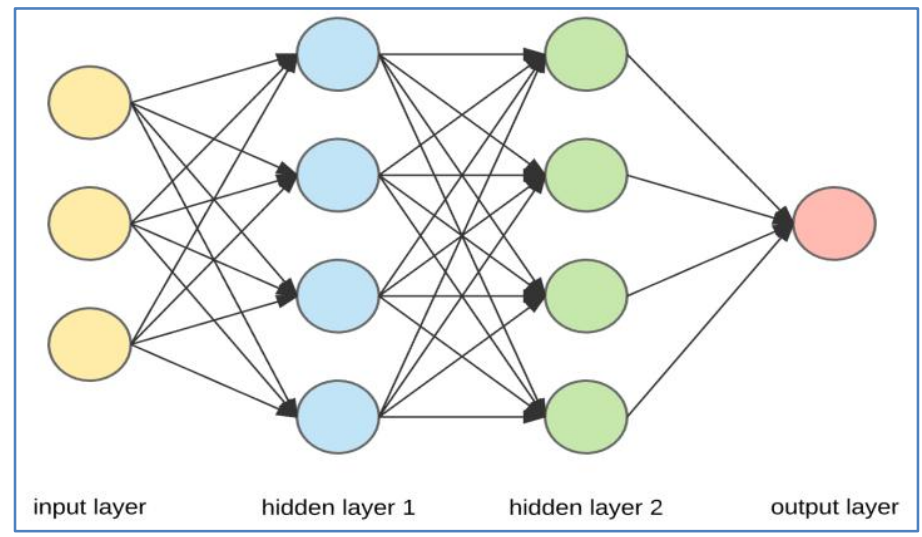

Fig-3: Full connected multilayer feed-forward neural network

\section{RESULTS AND DisCUSSION}

\section{Electrical Resistivity Test Measurements at different contaminated conditions}

Dry Condition

The electrical resistivity (ohm.cm) for epoxy has been investigated with different micro fillers type and concentration in dry condition. Fig-4 shows the relation of electrical resistivity and different percentages of micro $\mathrm{SiO}_{2}$ and $\mathrm{Ba}\left(\mathrm{IO}_{3}\right)_{2}$ fillers added to epoxy in dry condition.

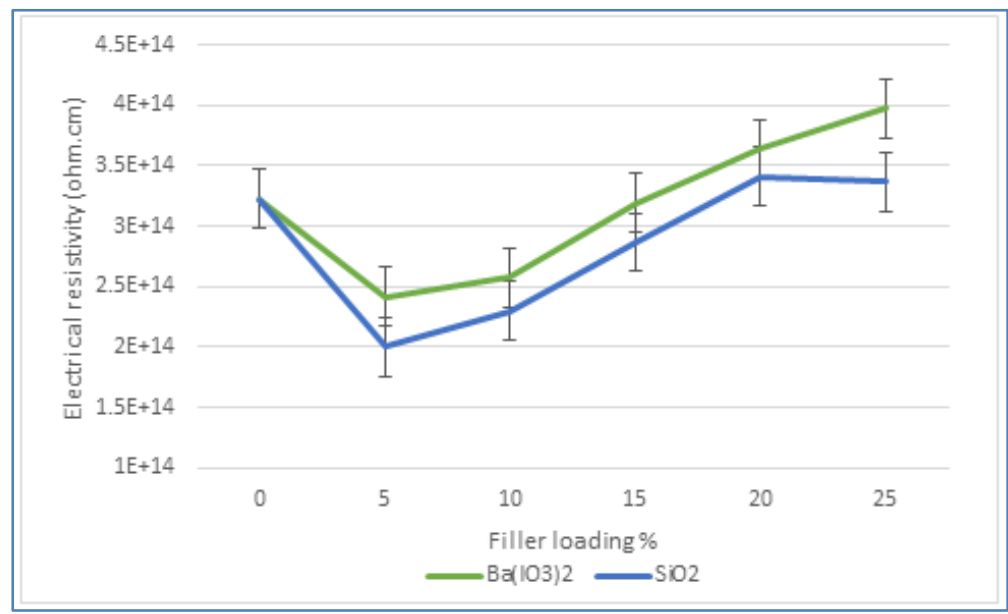

Fig-4: Electrical resistivity of micro composite loaded with different types and concentrations of fillers in dry condition

The electrical resistivity (ohm.cm) is measured for micro composite samples Fig-4. The increase of filler micro $\mathrm{SiO}_{2}$ and $\mathrm{Ba}\left(\mathrm{IO}_{3}\right)_{2}$ fillers concentration results in increasing the electrical resistivity. Fig-4. shows that the epoxy composite with $25 \mathrm{wt} \%$ micro $\mathrm{Ba}\left(\mathrm{IO}_{3}\right)_{2}$ filler records maximum electrical resistivity at $3.98 \times 10^{14} \mathrm{ohm} . \mathrm{cm}$. When the filler type also changes, the electrical resistivity of composite material changes.

\section{Wet Condition}

After immersion in a container of distilled water as a simulation of wet weather and rains the samples are tested for electrical resistivity. Fig-5 shows the relation of electrical resistivity and different percentages of micro $\mathrm{SiO}_{2}$ and $\mathrm{Ba}\left(\mathrm{IO}_{3}\right)_{2}$ fillers added to epoxy in wet condition. 


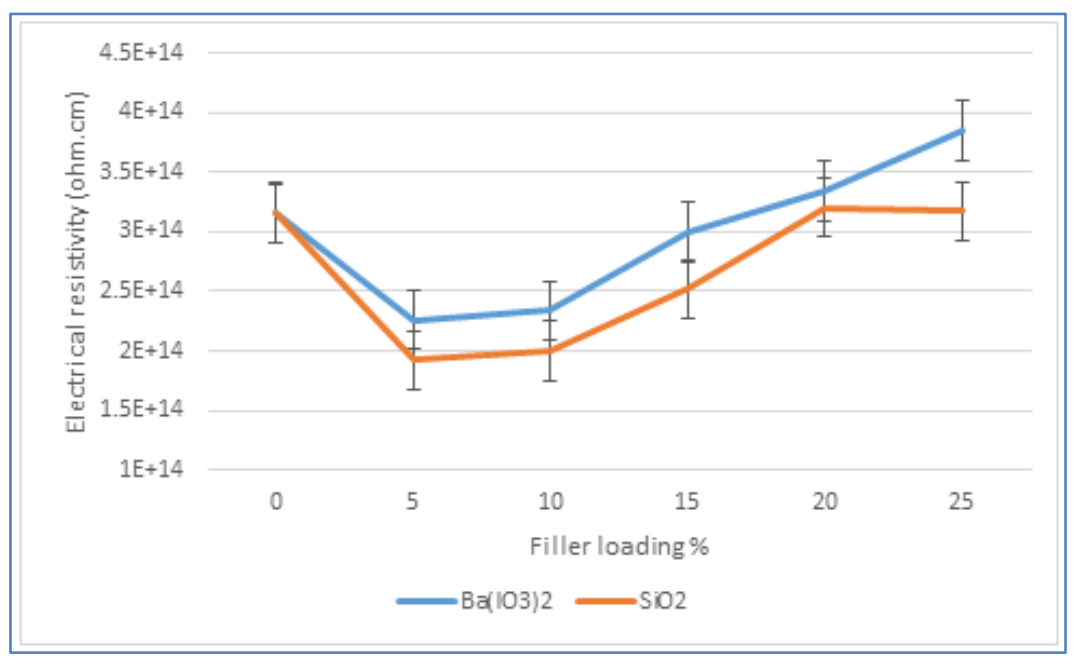

Fig-5: Electrical resistivity of micro composite loaded with different types and concentrations of fillers in wet condition

The results showed that after adding different fillers, the electrical resistivity (ohm.cm) of epoxy has been improved significantly. It is obviously shown in Fig-5. that with the increase of filler content (from 0\% to 25\%), the electrical resistivity (ohm.cm) of epoxy is increased. The electrical resistivity (ohm.cm) of micro Barium iodate composite is higher than micro silicon dioxide composite. The electrical resistivity (ohm.cm) of micro Barium iodate composite increases and reaches the highest value of $3.85 \times 10^{14} \mathrm{ohm} . \mathrm{cm}$ at the percentage of $25 \mathrm{wt} \%$ as shown in Fig-5.

\section{Salty Wet Condition}

For a simulation of areas near to seas or coastal cities, samples are immersed into a container of $\mathrm{NaCl}$ solution and tested for electrical resistivity (ohm.cm). Fig-6 shows the relation of electrical resistivity (ohm.cm) and different percentages of micro $\mathrm{SiO}_{2}$ and $\mathrm{Ba}\left(\mathrm{IO}_{3}\right)_{2}$ fillers added to epoxy in salty wet condition.

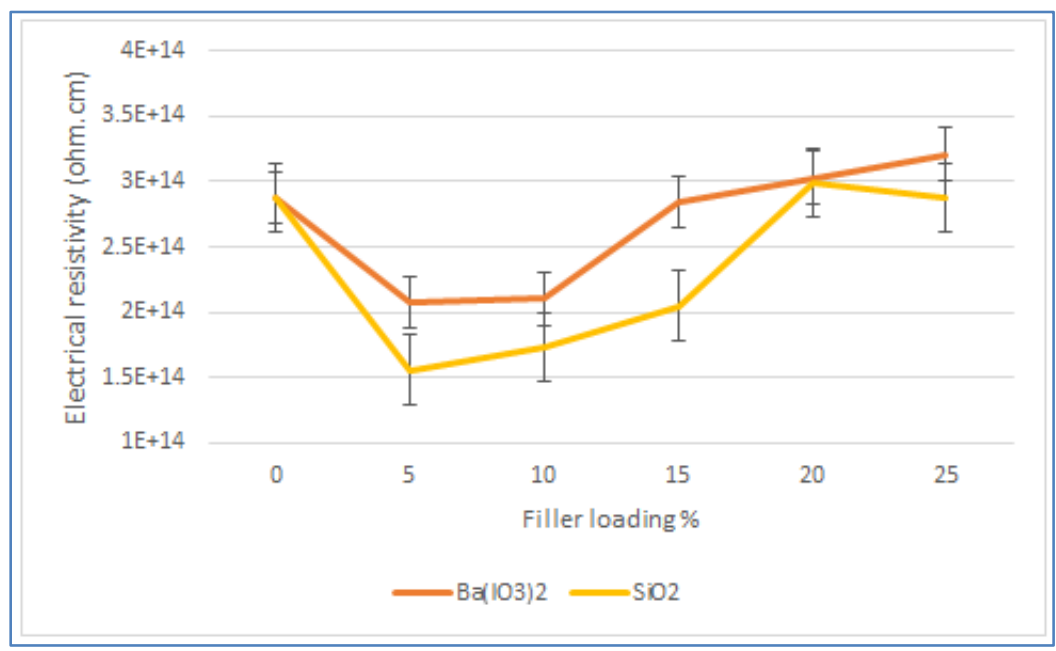

Fig-6: Electrical resistivity of micro composite loaded with different types and concentrations of fillers in salty wet condition

Clearly the presence of micro Barium iodate filler has offered appreciable electrical resistivity (ohm.cm) in comparison to pure epoxy. It can be shown from Fig-6 that, the maximum electrical resistivity (ohm.cm) is recorded for micro Barium iodate composites with the content of $25 \mathrm{wt} \%$, but micro silicone dioxide composite has the maximum electrical resistivity (ohm.cm) when the filler concentration is $20 \mathrm{wt} \%$. With increasing the concentration of micro silicone dioxide filler up to $20 \%$, the electrical resistivity (ohm.cm) showed an enhanced performance as shown in Fig-6.

\section{Artificial Neural Network Results}

The experimental measurements of electrical resistivity (ohm.cm) of different epoxy composite samples were used to train the ANN model. The ANN model has two inputs (the content of $\mathrm{SiO}_{2}$ and $\mathrm{Ba}\left(\mathrm{IO}_{3}\right)_{2}$ fillers in epoxy and the test condition); the output is the electrical resistivity (ohm.cm). The feed-forward neural network model that has been used was built by writing m-file code using MATLAB neural network toolbox [12]. 
ANN Model for Estimating Electrical Resistivity (ohm.cm) of Micro Ba( $\left.\mathrm{IO}_{3}\right)_{2}$ Composites in Different Contaminated Condition

Table-2, and Fig-7 show the test results of ANN model in different contaminated conditions such as dry, wet and salty wet.

Table-2: ANN and experimental results for electrical resistivity of micro $\mathrm{Ba}\left(\mathrm{IO}_{3}\right)_{2}$ /epoxy composites in different contaminated conditions

\begin{tabular}{|c|c|c|c|c|}
\hline \multirow{2}{*}{ Composite code } & \multirow{2}{*}{ Condition of test } & \multicolumn{3}{|c|}{ Electrical Resistivity (ohm.cm) } \\
\hline & & Experimental results & ANN results & Residual $\left(\mathrm{O}_{\text {act. }}-\mathrm{O}_{\mathrm{NN}}\right)(\%)$ \\
\hline $\mathrm{P}$ & \multirow{6}{*}{ Dry } & $3.23 * 10^{14}$ & $3.1400 * 10^{14}$ & 2.7863 \\
\hline $\mathrm{Ba}_{5}$ & & $2.42 * 10^{14}$ & $2.4635 * 10^{14}$ & 1.7975 \\
\hline $\mathrm{Ba}_{10}$ & & $2.58 * 10^{14}$ & $2.5161 * 10^{14}$ & 2.4767 \\
\hline $\mathrm{Ba}_{15}$ & & $3.19 * 10^{14}$ & $3.0906 * 10^{14}$ & 3.1159 \\
\hline $\mathrm{Ba}_{20}$ & & $3.64 * 10^{14}$ & $3.5444 * 10^{14}$ & 2.6263 \\
\hline $\mathrm{Ba}_{25}$ & & $3.98 * 10^{14}$ & $3.8646 * 10^{14}$ & 2.8994 \\
\hline $\mathrm{P}$ & \multirow{6}{*}{ Wet } & $3.16^{*} 10^{14}$ & $3.1400 * 10^{14}$ & 0.6329 \\
\hline $\mathrm{Ba}_{5}$ & & $2.26 * 10^{14}$ & $2.4234 * 10^{14}$ & 7.2301 \\
\hline $\mathrm{Ba}_{10}$ & & $2.34 * 10^{14}$ & $2.5160 * 10^{14}$ & 7.5213 \\
\hline $\mathrm{Ba}_{15}$ & & $3.00 * 10^{14}$ & $3.0905 * 10^{14}$ & 3.0166 \\
\hline $\mathrm{Ba}_{20}$ & & $3.34 * 10^{14}$ & $3.5442 * 10^{14}$ & 6.1137 \\
\hline $\mathrm{Ba}_{25}$ & & $3.85 * 10^{14}$ & $3.8645 * 10^{14}$ & 0.3766 \\
\hline $\mathrm{P}$ & \multirow{6}{*}{ Salty wet } & $2.58 * 10^{14}$ & $2.5637 * 10^{14}$ & 0.6317 \\
\hline $\mathrm{Ba}_{5}$ & & $2.07 * 10^{14}$ & $2.2037 * 10^{14}$ & 6.4589 \\
\hline $\mathrm{Ba}_{10}$ & & $2.1 * 10^{14}$ & $2.1278 * 10^{14}$ & 1.3238 \\
\hline $\mathrm{Ba}_{15}$ & & $2.84 * 10^{14}$ & $2.7911 * 10^{14}$ & 1.7218 \\
\hline $\mathrm{Ba}_{20}$ & & $3.03 * 10^{14}$ & $2.9981 * 10^{14}$ & 1.0528 \\
\hline $\mathrm{Ba}_{25}$ & & $3.21 * 10^{14}$ & $3.0275 * 10^{14}$ & 5.6853 \\
\hline
\end{tabular}

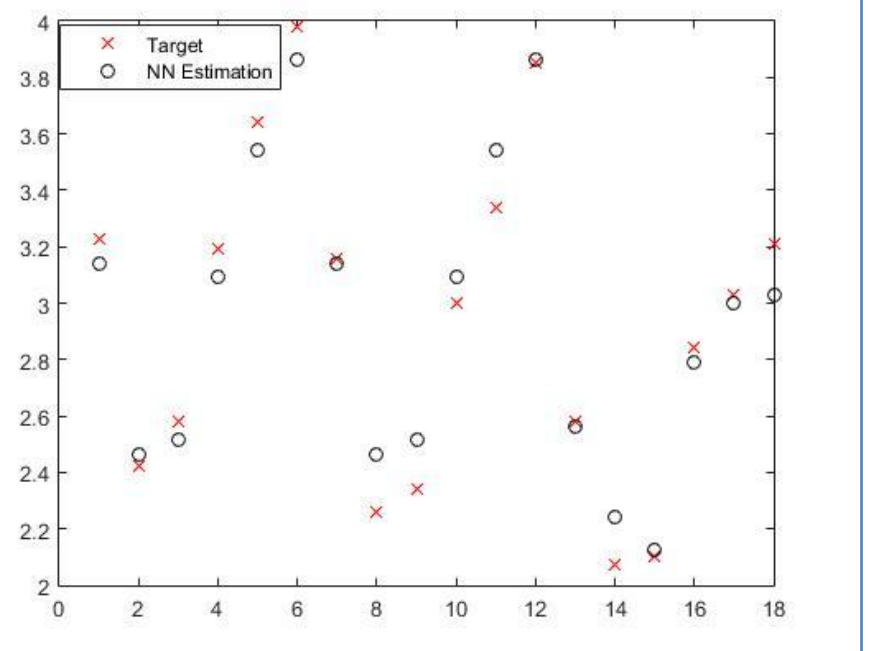

Fig-7: ANN results for the electrical resistivity of $\mathrm{Ba}\left(\mathrm{IO}_{3}\right)_{2} /$ epoxy composite samples under different contaminated conditions

It can be noted from Table-2 and Fig-7 that ANN model has been trained which can evaluate the electrical resistivity (ohm.cm) of different concentrations of $\mathrm{Ba}\left(\mathrm{IO}_{3}\right)_{2}$ in epoxy composites. The average percentage of errors was evaluated for $\mathrm{ANN}$ model and ranging from $0.3766 \%$ for sample $\mathrm{Ba}_{25}$ to $7.2301 \%$ for sample $\mathrm{Ba}_{5}$ as shown in Table-2.

\section{ANN Model for Estimating Electrical Resistivity of Micro SiO ${ }_{2}$ Composites in Different Contaminated Conditions}

Table-3, and Fig-8 show the test results of ANN model in different contaminated conditions such as dry, wet and salty wet. 
Table-3: ANN and experimental results for electrical resistivity (ohm.cm) of micro $\mathrm{SiO}_{2} /$ epoxy composites in different contaminated conditions

\begin{tabular}{|c|c|c|c|c|}
\hline \multirow{2}{*}{ Composite code } & \multirow{2}{*}{ Condition of test } & \multicolumn{3}{|c|}{ Electrical Resistivity (ohm.cm) } \\
\hline & & Experimental results & ANN results & Residual $\left(\mathrm{O}_{\text {act. }}-\mathrm{O}_{\mathrm{NN}}\right)(\%)$ \\
\hline $\mathrm{P}$ & \multirow{6}{*}{ Dry } & $3.23 * 10^{14}$ & $3.1600 * 10^{14}$ & 2.1671 \\
\hline $\mathrm{Si}_{5}$ & & $2.00 * 10^{14}$ & $1.9874 * 10^{14}$ & 0.6300 \\
\hline $\mathrm{Si}_{10}$ & & $2.30 * 10^{14}$ & $2.1213 * 10^{14}$ & 7.7695 \\
\hline $\mathrm{Si}_{15}$ & & $2.87 * 10^{14}$ & $2.6805 * 10^{14}$ & 6.6027 \\
\hline $\mathrm{Si}_{20}$ & & $3.41 * 10^{14}$ & $3.185^{*} 10^{14}$ & 6.4956 \\
\hline $\mathrm{Si}_{25}$ & & $3.37 * 10^{14}$ & $3.2704 * 10^{14}$ & 2.9554 \\
\hline $\mathrm{P}$ & \multirow{6}{*}{ Wet } & $3.16^{*} 10^{14}$ & $3.1599 * 10^{14}$ & 0.0031 \\
\hline $\mathrm{Si}_{5}$ & & $1.92 * 10^{14}$ & $1.9874 * 10^{14}$ & 3.5104 \\
\hline $\mathrm{Si}_{10}$ & & $2.00 * 10^{14}$ & $2.1213 * 10^{14}$ & 6.0650 \\
\hline $\mathrm{Si}_{15}$ & & $2.52 * 10^{14}$ & $2.5805 * 10^{14}$ & 2.4007 \\
\hline $\mathrm{Si}_{20}$ & & $3.20 * 10^{14}$ & $3.1285 * 10^{14}$ & 2.2343 \\
\hline $\mathrm{Si}_{25}$ & & $3.17 * 10^{14}$ & $3.2704 * 10^{14}$ & 3.1671 \\
\hline $\mathrm{P}$ & \multirow{6}{*}{ Salty wet } & $2.58 * 10^{14}$ & $3.0729 * 10^{14}$ & 7.4181 \\
\hline $\mathrm{Si}_{5}$ & & $1.56^{*} 10^{14}$ & $1.5923 * 10^{14}$ & 2.0705 \\
\hline $\mathrm{Si}_{10}$ & & $1.73 * 10^{14}$ & $1.6830 * 10^{14}$ & 2.7167 \\
\hline $\mathrm{Si}_{15}$ & & $2.05 * 10^{14}$ & $2.0568 * 10^{14}$ & 0.3317 \\
\hline $\mathrm{Si}_{20}$ & & $2.99 * 10^{14}$ & $2.7866 * 10^{14}$ & 6.8026 \\
\hline $\mathrm{Si}_{25}$ & & $2.88 * 10^{14}$ & $2.9202 * 10^{14}$ & 1.3958 \\
\hline
\end{tabular}

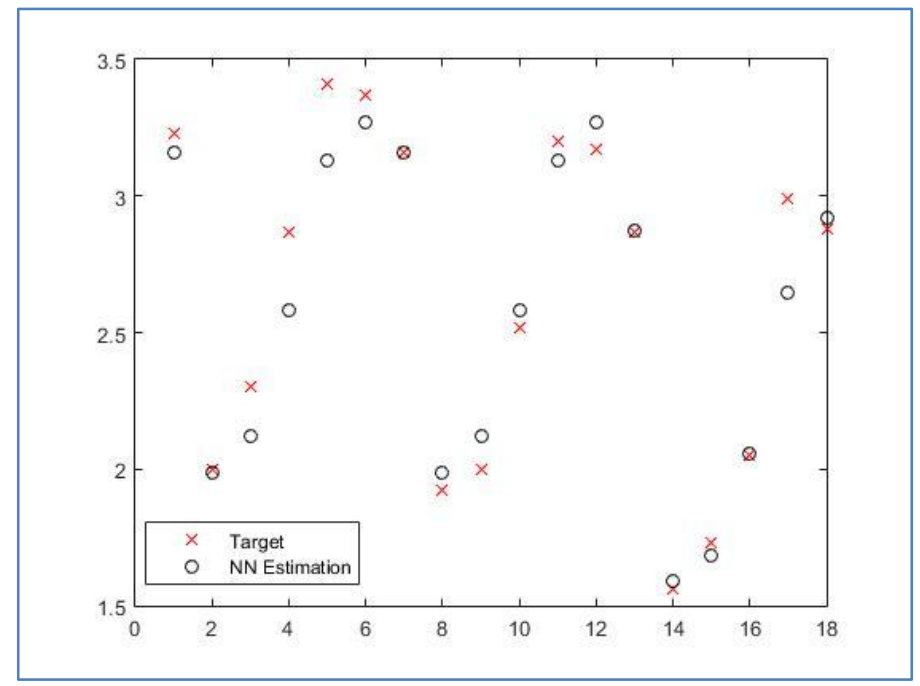

Fig-8: ANN results for the electrical resistivity of $\mathrm{SiO}_{2}$ /epoxy composite samples under different contaminated conditions

It can be noted from Table-3 and Fig- 8 that ANN model has been trained which can evaluate the electrical resistivity (ohm.cm) of different concentrations of $\mathrm{SiO}_{2}$ in epoxy composites. The average percentage of errors was evaluated for ANN model and ranging from $0.0031 \%$ for sample $\mathrm{P}$ to $7.7695 \%$ for sample $\mathrm{Si}_{5}$ as shown in Table-3.

\section{CONCLUSION}

The following conclusions can be drawn from this study

The electrical resistivity (ohm.cm) has been improved by adding filler to epoxy resin.

1. The electrical resistivity (ohm.cm) of different fillers decreased in wet and salty wet conditions as compared with those in dry condition.

2. Electrical properties of epoxy composite filled with $\mathrm{Ba}\left(\mathrm{IO}_{3}\right)_{2}$ are reliable at $25 \mathrm{wt} \%$ and have better electrical resistivity than $\mathrm{SiO}_{2}$ composites.

3. Artificial neural network model reduces the high cost of multiple measurements.

4. The optimum percentage of Barium iodate that could be adopted in the epoxy samples is $25 \mathrm{wt} \%$. 


\section{REFERENCES}

1. Odegard, G. M., \& Bandyopadhyay, A. (2011). Physical aging of epoxy polymers and their composites. Journal of polymer science Part B: Polymer physics, 49(24), 1695-1716.

2. Kremer, F., \& Schönhals, A. (Eds.). (2002). Broadband dielectric spectroscopy. Springer Science \& Business Media.

3. Klampar, M., \& Liedermann, K. (2012, June). Dielectric relaxation spectroscopy of epoxy resins with $\mathrm{TiO} 2$, Al 2 O 3, WO 3 and SiO 2 nanofillers. In 2012 IEEE International Symposium on Electrical Insulation (pp. 637-640). IEEE.

4. Delor-Jestin, F., Drouin, D., Cheval, P. Y., \& Lacoste, J. (2006). Thermal and photochemical ageing of epoxy resinInfluence of curing agents. Polymer Degradation and Stability, 91(6), 1247-1255.

5. Cerveny, S., Arrese-Igor, S., Dolado, J. S., Gaitero, J. J., Alegría, A., \& Colmenero, J. (2011). Effect of hydration on the dielectric properties of CSH gel. The Journal of chemical physics, 134(3), 034509.

6. Dakin, T. W. (1974). Application of epoxy resins in electrical apparatus. IEEE Transactions on Electrical Insulation, (4), 121-128.

7. McAdams, L. V., Gannon, J. A., \& Kroschwitz, J. (1991). High performance polymers and composites. JI Kroschwitz edition, John Wiley \& Sons, Inc, 258-318.

8. Kyoritsu Electrical Instruments Works, LTD., http://www.kew-ltd.cp.jp.

9. Instruction Manawal 4-range High voltage insulation resistance tester, Model 3125, http://www.kew-ltd.cp.jp

10. Hornik, K., Stinchcombe, M., \& White, H. (1989). Multilayer feedforward networks are universal approximators. Neural networks, 2(5), 359-366.

11. Simon, H. (1999). Neural Networks: A Comprehensive Foundation. $2^{\text {nd }}$ Edition, Pearson

12. Qenawy, S., Nasrat, L., Ismail, H. M., \& Asaad, J. (2020). Feed Forward Neural Network to Predict Dielectric Strength of SiR/TiO2 Composites. IET Nanodielectrics. 